\section{Don't touch that dial}

\section{J. W. C. White}

AT a time when superlatives are routinely used to describe the mundane, it is difficult to express the importance of two papers in this issue which present results from the new GRIP ice core in central Greenland. The GRIP Project Members ${ }^{1}$ and Dansgaard et al. ${ }^{2}$ (pages 203 and 218, respectively) give us our first detailed look at the last interglacial period, and it is not what we expected.

As an uncertain climate lies before us, we have been looking warily over our shoulders to see how the climate system has behaved in the past. For 10,000 years, the Earth has enjoyed an interglacial period, a time of steady and dependable climate. Further back, during the last ice age (which lasted about 100,000 years), and in the transitional period, it is now accepted that the climate 'flickered' rapidly. But we could take comfort from the thought that dramatic changes occurring in decades or even years were probably triggered in some way by the massive glaciers or huge extensions of sea ice present at the time.

Now the Greenland Ice-core Project (GRIP) team have removed this sense of security. Using a variety of evidence drawn from the ice core - stable isotope ratios, chemical and physical properties, and greenhouse gas concentrations in trapped air bubbles - they demonstrate that very rapid shifts in temperature and greenhouse gases are also possible in interglacial periods.

Our view of climate on the timescale of glacial cycles is shaped by the tools we use to construct that view. Up to now, our ideas of interglacial periods have come from three sources. First and foremost is our knowledge of our own Holocene interglacial, drawn from sources such as tree rings, historical records and pollen samples, to name but a few. Then there are the ocean sediment cores which document numerous interglacials over the past million years. Third, there is the Vostok ice core, until now the only deep core to have yielded easily datable ice from the previous interglacial period (known as the Eemian) which stretched from about 135,000 to 115,000 years ago.

In ocean cores the stirring of the sediment surface by benthic life homogenizes the oceanic record so that the minimum resolution is no better than a thousand years. In the Vostok core, the low accumulation rate of snow and thinning of the annual layers with depth means that climate changes of a century or less are difficult to resolve; flickers may have occurred that cannot now be detected. (There is a compensation: the Vostok core should take the record back to about
500,000 years ago, twice the age of the oldest Greenland ice ${ }^{3}$, and covering several glacial to interglacial cycles.)

The new Greenland ice cores GRIP and GISP2, in contrast, were drilled in regions of high snow accumulation near the centre of the Greenland ice sheet. With these cores, designed to concentrate on the past 200,000 years, we can see climate changes on the timescale of decades or less, even though they occurred a hundred thousand years ago. The indicators of climate change range from local (for example, temperature, deduced from its effect on stable isotope ratios), to regional and

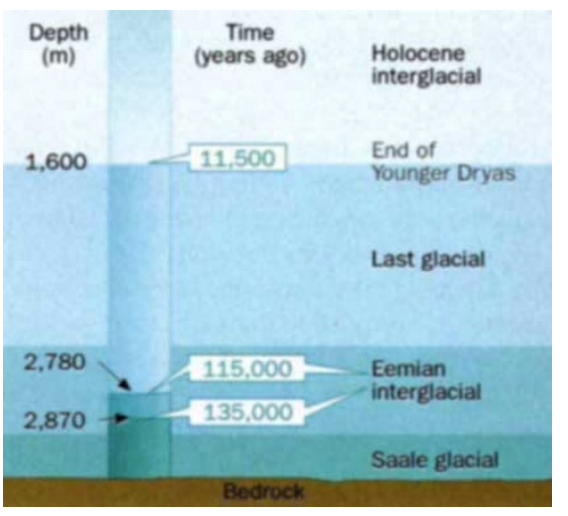

Depths of time - the GRIP ice core.

hemispheric (such as airborne dust concentrations and chemical composition), to global (greenhouse gas compositions)

The Eemian period falls in the interval from 2,780 to $2,870 \mathrm{~cm}$ down, well above bedrock. Blurred in the Vostok core, it now comes into focus and it is strikingly different from the Holocene. Holocene climate appears to have one, and only one, state, whereas the new results show that the Eemian had three. The middle state matches our own Holocene climate. A significantly colder state and a significantly warmer state existed in the Eemian. On average, temperatures were $2^{\circ} \mathrm{C}$ higher than at present. It apparently took very little time, perhaps less than a decade or two, to shift between the states, and the states appear to be stable sometimes for thousands of years and sometimes for only decades. We don't know which is the norm for interglacial periods: the stable, one-state Holocene or the multiple-state, rapidly changing Eemian. We do know that answering this question will be a priority for global change research.

When evidence from the sister core of GRIP, the GISP2 core ${ }^{4,5}$, showed earlier this year that aspects of the climate system could shift from glacial conditions to interglacial conditions in a few years, there was always the solace that such changes were characteristic of glacial times, and not really analogues of the future. In our interglacial age, we do not expect the polar front in the North Atlantic rapidly to dip down to Spain with sea ice expanding in behind it, plunging adjacent land, particularly Northern Europe, into glacial-like cold. We do not have massive lakes formed by retreating glaciers, lakes which may catastrophically drain into the North Atlantic, disrupting deep water formation and the transfer of heat northward.

The new ice core results bring rapid climate change to our doorstep: changes of up to $10^{\circ} \mathrm{C}$ in a couple of decades, or perhaps in less than a decade, appear possible in interglacials. Given our ongoing 'global experiment' of increasing greenhouse gas concentrations via fossil fuel burning, is the Eemian warm state a glimpse at our future climate? Whatever the answer to that question, the speed with which the climate system can shift states gives us pause. Adaptation - the peaceful shifting of food growing areas, coastal populations and so on - seemed possible, if difficult, when abrupt change meant a few degrees in a century. It now seems a much more formidable task, requiring global cooperation with swift recognition and response.

How unusual is the climate stability of the Holocene? Dansgaard and colleagues ${ }^{2}$ investigated one of the possible tracers, the oxygen isotope ratio (a proxy for atmospheric temperature) along the whole of the GRIP core (see figure). Throughout the last glacial period, the Eemian interglacial and the glacial before that, they found rapid oscillations in the isotope ratio. Because of the way that ice thins with age, they could look in detail at the Holocene, and found that the swings have been much smaller, by a factor of 3 to 4 , than those earlier flickers. At no time during the Holocene has Eemian-like climate change occurred.

We humans have built a remarkable socio-economic system during perhaps the only time when it could be built, when climate was stable enough to let us develop the agricultural infrastructure required to maintain an advanced society. We don't know why we have been so blessed, but even without human intervention, the climate system is capable of stunning variability. If the Earth had an operating manual, the chapter on climate might begin with a caveat that the system has been adjusted at the factory for optimum comfort, so don't touch the dials.

J. W. C. White is at the Institute of Arctic and Alpine Research, University of Colorado, Boulder, Colorado 80309, USA.

\footnotetext{
1. GRIP Project Members Nature 364, 203-207 (1993)

2. Dansgaard, W. et al. Nature 364, 218-220 (1993)

3. Jouzel, J. et al. Nature (in the press)

4. Alley, R. et al. Nature 362, 527-529 (1993).

5. Taylor, K. C. et al. Nature 361, 432-436 (1993).
} 